\title{
Research on Influence of Stone Powder Content and Water- binder Ratio on Optimal Gradation of Manufactured Sand
}

\author{
Cheng $\mathrm{Yi}^{1}$, Zhang Dong*2 \\ ${ }^{1}$ Hangzhou Urban Expressway Co., Ltd. Hangzhou \\ ${ }^{2}$ Research Institute of Highway Ministry of Transport, Beijing, 100088, China
}

\begin{abstract}
The poor gradation of manufactured sand limits the application in concrete work. Hence, in order to study the influence of the gradation of manufactured sand on the performance of mortar, this paper removes the stone powder from the manufactured sand, increases the content of different sands based on the mid-value of gradation, mixes it with different proportions of stone powder and tests the expansion degree of mortar with the water-binder ratio of $0.35,0.4$ and 0.45 respectively. The test results show that the influence of the gradation of manufactured sand on the expansion degree of mortar depends on the stone powder content and water-binder ratio. When the stone powder content is less than $5 \%$, the expansion degree of motor will be reduced with the gradation adjustment; if the stone powder content is more than $5 \%$, the expansion degree of mortar will show different characteristics with the gradation adjustment under different water-binder conditions.
\end{abstract}

\section{Introduction}

Manufactured sand has been used in foreign countries for several decades, especially in some countries and regions with poor natural sand resources, more stones and less sand, accounting for a large proportion in fine aggregate. However, due to the differences in mother rock, production equipment and process, the gradation of manufactured sand also varies considerably in different countries [1-3]. Therefore, many countries have successively formulated applicable gradation standards for manufactured sand. In the meantime, China has also studied the application of manufactured sand since 1970s and introduced some industrial and local standards one after another [4].

Although manufactured sand has been following the standard of natural sand, some scholars believe that the gradation standard of fine aggregate is only suitable for spherical particles, but not for non-spherical manufactured sand. On the one hand, good concrete may not be prepared according to the specification of fine aggregate, but slight adjustment of gradation can produce concrete with better performance. On the other hand, the rheological property of concrete slurry is determined by cementitious material, fine aggregate and coarse aggregate. Cementitious material is mixed with water to form slurry, wraps the fine aggregate to form mortar and further wrapped with mortar to reduce the friction between stones. Furthermore, surplus mortar is filled in the gap and finally forms a mixture. Therefore, the rheological properties of mortar can greatly affect the overall workability of concrete. However, the amount of powder must be controlled in a suitable range, since too much powder may make the mortar sticky, while too little powder may reduce the fluidity of mortar due to no slurry wrapping the gravel. Thus, both the stone powder content and water-binder ratio (the amount of cementitious material) of concrete system shall be considered comprehensively when studying the reasonable gradation of manufactured sand.

\section{Test}

\subsection{Test materials}

The cementitious material used in the test is P.O 42.5 ordinary Portland cement produced by Taizhou $\mathrm{CONCH}$, the manufactured sand and stone powder are produced by Damaiyu Manufactured Sand Base in Yuhuan, Zhejiang, the stone powder is 200-mesh tuff powder, and the manufactured sand is tuff manufactured sand with $9.7 \%$ stone powder content. See Table 1 for the specific performance. The coarse aggregate is tuff macadam with two gradations of $4.75-16 \mathrm{~mm}$ and $16-25 \mathrm{~mm}$ and the mixing ratio of $3: 7$; the additive is polycarboxylate superplasticizer produced by Zhejiang WULONG, with the water reduction rate of $25 \%$. 
Table 1 Physical performance indexes of manufactured sand

\begin{tabular}{c|c|c|c|c|c|c|c}
\hline \multicolumn{2}{c|}{ Density $\left(\mathrm{kg} / \mathrm{m}^{3}\right)$} & $\begin{array}{c}\text { Crushing } \\
\text { value } \\
(\%)\end{array}$ & $\begin{array}{c}\text { MB } \\
\text { value } \\
(\%)\end{array}$ & $\begin{array}{c}\text { Stone powder } \\
\text { content } \\
(\%)\end{array}$ & $\begin{array}{c}\text { Water } \\
\text { Apporption } \\
(\%)\end{array}$ & $\begin{array}{c}\text { Porosity } \\
(\%)\end{array}$ & $\begin{array}{c}\text { Fineness } \\
\text { modulus }\end{array}$ \\
\hline 2635 & 1555 & 10.6 & 0.4 & 9.7 & 1.9 & 41 & 3.04 \\
\hline
\end{tabular}

\subsection{Test method}

Generally, $0.35,0.4$ and 0.45 are the most common waterbinder ratios of concrete, covering the general strength grade of concrete such as $\mathrm{C} 30, \mathrm{C} 40$ and $\mathrm{C} 50$. Therefore, this paper studies the gradation optimization of manufactured sand under the conditions of three waterbinder ratios, and designs 5 gradations of manufactured sand as shown in Table 2.

Table 2 Gradation adjustment method of manufactured sand

\begin{tabular}{c|c|c|c|c|c|c|c|c}
\hline \multirow{2}{*}{ Number } & \multicolumn{7}{|c|}{ Proportion of particle size } & $\begin{array}{c}\text { Fineness } \\
\text { modulus }\end{array}$ \\
\cline { 2 - 9 } & $4.75 \mathrm{~mm}$ & $2.36 \mathrm{~mm}$ & $1.18 \mathrm{~mm}$ & $0.6 \mathrm{~mm}$ & $0.3 \mathrm{~mm}$ & $0.15 \mathrm{~mm}$ & $0.075 \mathrm{~mm}$ & 5 \\
\hline J1 & 5 & 7.5 & 17.5 & 25.5 & 25.5 & 14 & 2.62 \\
\hline J2 & 4.5 & 16.75 & 15.75 & 22.95 & 22.95 & 12.6 & 4.5 & 2.84 \\
\hline J3 & 4.5 & 6.75 & 25.75 & 22.95 & 22.95 & 12.6 & 4.5 & 2.71 \\
\hline J4 & 4.5 & 6.75 & 15.75 & 32.95 & 22.95 & 12.6 & 4.5 & 2.57 \\
\hline J5 & 4.5 & 6.75 & 15.75 & 22.95 & 32.95 & 12.6 & 4.5 & 2.44 \\
\hline J6 & 4.5 & 6.75 & 15.75 & 22.95 & 22.95 & 22.6 & 4.5 & 2.30 \\
\hline
\end{tabular}

According to Manufactured sand for cement concrete in highway engineering (JT/T 819-2011), all gradations of manufactured sand are located within the gradation range of sand in Area II. In order to simplify the test, the concrete is replaced by mortar in corresponding mix proportions, and the influence of gradation adjustment of manufactured sand on the slurry fluidity is quantized with the expansion degree of mortar. The test is carried according to the provisions of "Rapid test method for compatibility of concrete admixtures" in Appendix A of Code for concrete admixture application (GB 50119-2013). Besides, stone powder $(5 \%, 7.5 \%$ and $10 \%)$ is mixed into the manufactured sand in addition to the gradation adjustment, so as to study the influence of stone powder content on the overall fluidity of slurry and the interaction with gradation. The mortar mix ratio is shown as the following table:

Table 3 Mortar mix ratio

\begin{tabular}{|c|c|c|c|c|c|c|}
\hline \multirow[b]{2}{*}{$\begin{array}{l}\text { Water-binder } \\
\text { ratio }\end{array}$} & \multicolumn{6}{|c|}{ Material consumption per cubic meter $(\mathrm{kg})$} \\
\hline & $\begin{array}{l}\text { Stone powder } \\
\text { content }\end{array}$ & Water & Cement & $\begin{array}{l}\text { Manufactur } \\
\text { ed sand }\end{array}$ & $\begin{array}{l}\text { Stone } \\
\text { powder }\end{array}$ & $\begin{array}{c}\text { Water } \\
\text { reducing } \\
\text { agent }\end{array}$ \\
\hline \multirow{3}{*}{0.45} & $5 \%$ & \multirow{3}{*}{270} & 600 & 1140 & 60 & $0.7 \%$ \\
\hline & $7.5 \%$ & & 600 & 1110 & 90 & $0.9 \%$ \\
\hline & $10 \%$ & & 600 & 1080 & 120 & $1.1 \%$ \\
\hline \multirow{3}{*}{0.4} & $5 \%$ & \multirow{3}{*}{240} & 600 & 1140 & 60 & $1.1 \%$ \\
\hline & $7.5 \%$ & & 600 & 1110 & 90 & $1.2 \%$ \\
\hline & $10 \%$ & & 600 & 1080 & 120 & $1.4 \%$ \\
\hline \multirow{3}{*}{0.35} & $5 \%$ & \multirow{3}{*}{210} & 600 & 1140 & 60 & $1.3 \%$ \\
\hline & $7.5 \%$ & & 600 & 1110 & 90 & $1.4 \%$ \\
\hline & $10 \%$ & & 600 & 1080 & 120 & $1.5 \%$ \\
\hline
\end{tabular}

\section{Results and discussion}

\subsection{Test results}

The effect of gradation, stone powder content and waterbinder ratio (consumption of cementitious material) on the expansion degree of mortar and the relationship among them are shown as Figure 1. As the proportion of particle size increases, the expansion degree of mortar changes obviously, which is also affected by the stone powder content and the water-binder ratio. When the water-binder ratio is 0.45 and the proportion of each particle size is increased from large to small, the expansion degree decreases first and then increases, but the points with the largest expansion degree are not the same under different stone powder contents. When the water-binder ratio is 0.4 and the stone powder content is $10 \%$, the expansion degree of mortar does not show a downward trend but increases all the time after the gradation adjustment, then reaches the highest value when the content of $0.6 \mathrm{~mm}$ particles increases. When the stone powder content is $5 \%$ and $7.5 \%$ and the proportion of $2.36 \mathrm{~mm}$ particles increases, the expansion degree of mortar decreases first and then increases again, wherein the expansion degree is the 
largest when the stone powder content is $5 \%$ and the particle size is $1.18 \mathrm{~mm}$ or the stone powder content is $7.5 \%$ and the particle size is $0.6 \mathrm{~mm}$. When the water-binder ratio is 0.3 and the stone powder content is only $5 \%$, the

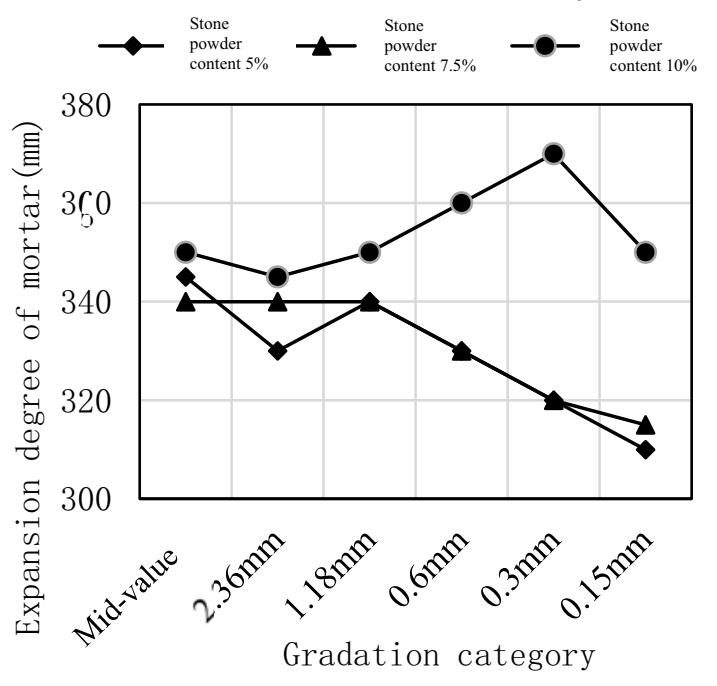

(a) $\mathrm{w} / \mathrm{c}=0.45$ expansion degree of mortar after gradation adjustment shows a tendency of first descending and then rising, while it reaches the maximum when the particle size is $0.6 \mathrm{~mm}$ under the rest two situations.
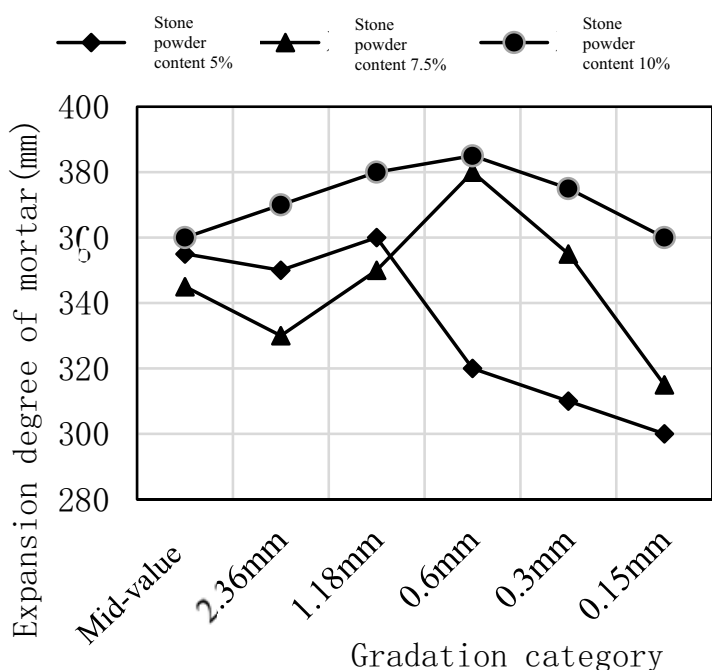

(b) $\mathrm{w} / \mathrm{c}=0.4$

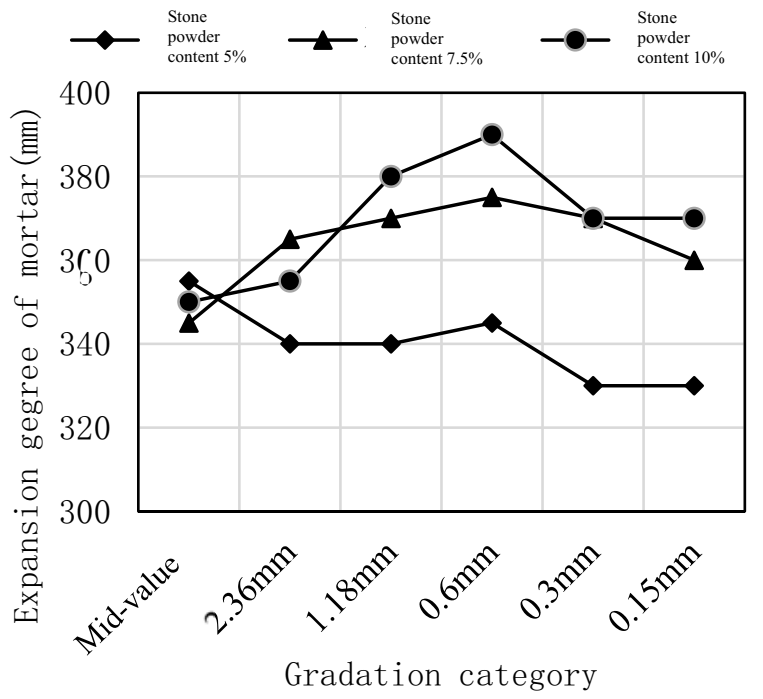

(c) $\mathrm{w} / \mathrm{c}=0.35$

Figure 1 Influence of water-binder ratio, stone powder content and gradation on expansion degree of mortar

\subsection{Influence of stone powder content and water-binder ratio on the optimal gradation}

By comparing the curves in Figure 1, it can be found that the expansion degree of mortar shows different rules when adjusting the gradation of manufactured sand under different water-binder ratios and stone powder content. If the stone powder content is only $5 \%$, the expansion degree of mortar after gradation adjustment shows a downward trend under any water-binder ratios; when the stone powder content is higher than $5 \%$ (except when the waterbinder ratio is 0.45), the expansion degree of mortar always increases first, then decreases and further reaches the maximum value when the particle size is $0.6 \mathrm{~mm}$ during gradation adjustment. On the other hand, Figure 2 shows the influence of water-binder ratio on the expansion degree of mortar after gradation adjustment when the stone powder content is $7.5 \%$, it can be seen that under different water-binder ratios, even if the stone powder content is the same, the expansion degree of mortar after gradation adjustment also presents different change rules, which indicates that the optimal gradation of manufactured sand can be affected by the stone powder content and water-binder ratio simultaneously. 


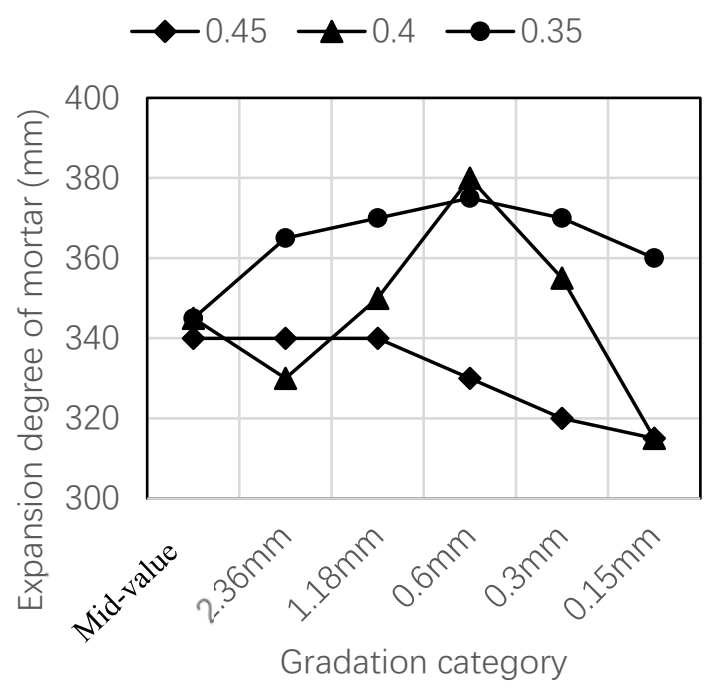

Figure 2 Influence of water-binder ratio on expansion degree of mortar when the stone powder content is $7.5 \%$

Obviously, the grain gradation of manufactured sand has a great impact on the performance of mortar. In addition, the cementitious material can form slurry to wrap the gravel, reduce the friction between particles and improve the mortar fluidity. For the manufactured sand, the function of stone powder in slurry is equal to cementitious material or powder. Therefore, when the water-binder ratio is large, the consumption of cementitious material shall be small. If the stone powder content in manufactured sand is low, there is no enough powder in the mortar to wrap the particles. Therefore, if the proportion of small-sized sand is increased, the slurry cannot fully wrap the particles, which may reduce the fluidity and expansion degree of mortar. However, if the stone powder content in the manufactured sand is high $(10 \%)$, there will be sufficient slurry to wrap the sand so that the fluidity of mortar can be improved. If the waterbinder ratio is small, the mortar itself contains enough powder, even though the stone powder content is not high, the increased small particles can be wrapped by enough slurry. Therefore, this is the reason for increasing the expansion degree of mortar. However, the increase of small particles is limited by the content of cementitious material and stone powder, and the fluidity of mortar may be reduced if the content of both materials is too little.

Besides, if the gradation is optimal, the increase of $2.36 \mathrm{~mm}$ particles can reduce the fluidity of mortar, while the increase of $1.18-0.6 \mathrm{~mm}$ particles may promote the fluidity of mortar. The distribution of particles in manufactured sand may have a dual effect on the fluidity of mortar. Firstly, the total specific surface area of sand may be decreased with the increase of large particles, which may reduce the amount of wrapped mortar, increase the amount of free water and movable mortar and promote the mortar fluidity; nevertheless, the larger the particle size, the greater the resistance to the mobility of mortar. Therefore, the increase of large particles would intensify the particle interlocking, block the flowing and have a deterioration effect on the mortar fluidity In other words, the former is a positive effect, while the latter is a negative effect, and there is an optimal particle size distribution range between the both. Hence, this experiment proves that in order to achieve the maximum fluidity of mortar, the gradation mid-value is not the best gradation of manufactured sand, and it is important to reduce the proportion of $4.75-2.36 \mathrm{~mm}$ particles and increase the proportion of $1.18-0.6 \mathrm{~mm}$ particles.

\section{Conclusion}

By comparing contents and water-binder ratios, it is found that the influence of manufactured sand on the mortar fluidity is not only related to its own gradation, but also to the water-binder ratio (consumption of cementitious material) and stone powder content. In general case, the stone powder content shall be kept at $7.5 \%-10 \%$, since the high content of stone powder can buffer the gradation change of manufactured sand concrete and easily prepare qualified concrete in actual production. Meanwhile, in order to improve the fluidity of mixture, it is necessary to increase the proportion of $1.18-0.6 \mathrm{~mm}$ particles so that the slurry can fully wrap the particles.ing the expansion degree of mortar after gradation adjustment under different stone powder

\section{References}

1. Xu Jian, Cai Jiwei, Wang Jiliang, et al. Research Status of Manufactured Sand and Manufactured Sand Concrete. [J] Science and Technology of Overseas Building Materials, 2004, 25 (3): 20-24.

2. Wang Jiliang. Research on Influence and Mechanism of Manufactured Sand on Concrete Performance [D]. Wuhan: Wuhan University of Technology, 2008.

3. $\mathrm{Hu}$ Jianwei and Wen Baolian. Influence Law and Action Effect of Gradation of Manufactured Sand on Performance of Cement Mortar. China Concrete, 2015,77:88-91.

4. Yin Zhisong, Zhou Yangming and Su Dengcheng. Influence of Limestone Powder on Microstructure and Mechanical Properties of Mortar [J]. Cement Engineering, 2009 (5): 12-16.

5. Wang Yuli, Xiong Zuqiang, Zhou Mingkai, et al. Experimental Study on Influence of Stone Powder Content on Performance of Manufactured Sand [J]. Journal of Henan Polytechnic University: Natural Science, 2009, 28 (2).

6. Ji Tao, Li Feng, Zhuang Yizhou, et al. Influence of Specific Surface Area of Manufactured Sand on Concrete Performance. Concrete, 2011 (2): 80-82.

7. Tang Xiangzheng, Some Problems During Application and Production of Artificial Sand in Yunnan Province [J], Yunnan Construction Materials, 2001 (4): 35-37.

8. GB/T 14684-2011, Sand for Construction [S]. Beijing: China Standard Press, 2011

9. GB/T 2419-2005, Test method for fluidity of cement mortar [S]. Beijing: China Standard Press, 2005 